\title{
The role of pulmonary resection in early stage small cell lung cancer
}

\author{
Dariusz Sagan $^{1, \mathrm{~A}-\mathrm{F} \oplus}$, Tomasz Galek ${ }^{2, \mathrm{~B}-\mathrm{D} \oplus}$, Tomasz Prystupa ${ }^{3, \mathrm{~B}-\mathrm{D} \odot}$ \\ ${ }^{1}$ Department of Thoracic Surgery, Medical University, Lublin, Poland \\ ${ }^{2}$ Dentado A. i T. Galek Group Physician-Dental Practice, Chełm, Poland \\ ${ }^{3}$ Independent Public Teaching Hospital no. 4 in Lublin, Lublin, Poland \\ A - Research concept and design, B - Collection and/or assembly of data, C - Data analysis and interpretation, \\ $D$ - Writing the article, E - Critical revision of the article, F - Final approval of the article
}

Sagan D, Galek T, Prystupa T. The role of pulmonary resection in early stage small cell lung cancer. J Pre-Clin Clin Res. 2021; 15(4): 199-203. doi: $10.26444 / j p c c r / 145094$

\begin{abstract}
Introduction and Objective. For many decades, small-Cell Lung Cancer (SCLC) has been considered a non-surgical disease and is traditionally managed by chemo- and radiotherapy. However, recent advances in early detection of pulmonary lesions have made it possible to detect small cell lung cancer at a very early stage of development. The aim of this review was to assess the current state of knowledge on the role of surgical pulmonary resection in patients with early stage SCLC, and to determine the optimal diagnostic and therapeutic strategy for patients with pulmonary nodules suspected for SCLC.

Review Methods. A literature search of the PubMed database was conducted using the key words: 'small cell lung cancer pulmonary resection not[non]' in the last 5 years. 99 manuscripts were found. Of these, only dealing directly with surgical pulmonary resection in SCLC were selected. Based on these criteria, 14 publications were identified and included in the review.

Brief description of the state of knowledge. Current scientific and clinical data reveal that surgical resection offers patients with SCLC considerable therapeutic benefits with favourably high overall survival rates. Analyzed reports showed that the local relapse rate in patients after surgical resection was significantly lower than in the non-surgical group. Furthermore, definitive surgical resection with adjuvant chemotherapy resulted in improved survival for patients with early stage SCLC, when compared to conservative approach.

Summary. Pulmonary resection of an early stage SCLC as a component of combined treatment offers considerable therapeutic benefits, among which almost $100 \%$ local control is of the greatest importance. Up-to-date clinical strategies strongly support the recommendation that peripheral pulmonary lesions suspected to be malign, should be surgically resected, unless serious contraindications are indicated.
\end{abstract}

\section{Key words}

surgery, cancer, lung, small-cell

\section{INTRODUCTION AND OBJECTIVE}

Small Cell Lung Cancer (SCLC) represents about 15\% - 20\% of al cases of lung cancer $[1,2]$, a highly malignant disease which clinically shows a strong tendency to disseminate early in the form of distant metastases [3, 4, 5]. Many patients present with rapid-onset symptoms due to extrathoracic distant spread, local tumour growth, or paraneoplastic syndromes [6].

During the $20^{\text {th }}$ century, the results of surgical treatment for SCLC were poor, mainly due to the fact that the disease was detected at an advanced stage of development $[6,7]$. As a result, it was therefore concluded that management of SCLC should be based on chemo- and radiotherapy, strategies that provide an early response rate of $80 \%-90 \%$. However, despite extensive research for new modalities to improve local control by aggressive radiotherapy supported by intensive systemic treatment, the majority of patients with SCLC finally experience either distant metastasis - predominantly to the brain, or local recurrence of the tumour.

The aim of this review was to assess the current state of knowledge about the role of surgical pulmonary resection in patients with early stage SCLC, and to determine optimal diagnostic and therapeutic strategy for patients with pulmonary nodules suspected for SCLC.

\section{REVIEW METHODS}

A literature search of the PubMed database (https://pubmed. ncbi.nlm.nih.gov/) was conducted using the key words: 'small cell lung cancer pulmonary resection not[non]' with the following filters applied: Free full text, Classical Article, Clinical Trial, Comparative Study, Journal Article, MetaAnalysis, Multicenter Study, Randomized Controlled Trial, Review, Systematic Review, in the last five years, Humans Ninety-nine manuscripts were found. Of these, only manuscrpits dealing directly with surgical pulmonary resection in SCLC were selected. Based on these criteria, 14 publications were identified and included in the review [8-21](Tab. 1). 
Table 1. Manuscripts included in the review.

\begin{tabular}{|c|c|c|c|c|c|}
\hline No. & Authors & Title & Source & $\begin{array}{c}\text { No. of } \\
\text { patients }\end{array}$ & Conclusions \\
\hline 1 & $\begin{array}{l}\text { Zhong L, Suo J, Wang } \\
\text { Y, Han J, Zhou H, Wei } \\
\text { H, Zhu J. }\end{array}$ & $\begin{array}{l}\text { Prognosis of limited-stage, } \\
\text { small cell lung cancer with } \\
\text { comprehensive treatment, } \\
\text { including radical resection }\end{array}$ & $\begin{array}{l}\text { World J Surg Oncol. } 2020 \text { Feb } \\
\text { 3;18(1):27. doi: 10.1186/s12957- } \\
\text { 020-1807-1. PMID: 32013993; } \\
\text { PMCID: PMC6998207. }\end{array}$ & 152 & $\begin{array}{l}\text { For LS-SCLC patients, the comprehensive treatment } \\
\text { including radical surgery (radical surgery + adjuvant } \\
\text { chemotherapy } \pm \text { adjuvant radiotherapy/neoadjuvant } \\
\text { chemotherapy + radical surgery + adjuvant } \\
\text { chemotherapy } \pm \text { adjuvant radiotherapy) may be superior } \\
\text { to concurrent chemoradiotherapy. }\end{array}$ \\
\hline
\end{tabular}

2 Lou $Y$, Zhong $R, X u J$, Does surgically resected Qiao R, Teng J, Zhang Y, small-cell lung cancer Zhang $X$, Chu T, Zhong without lymph node $\mathrm{H}$, Han B. involvement benefit
Thorac Cancer. 2020

May;11(5):1239-1244. doi: 10.1111/1759-7714.13381. Epub from prophylactic cranial irradiation?

2020 Mar 6. PMID: 32142599; PMCID: PMC7180625.

146 The evidence obtained does not support PCI therapy in the management of surgically resected SCLC with no lymph node involvement. KEY POINTS: Prophylactic cranial irradiation $(\mathrm{PCI})$ remains controversial for resected small-cell lung cancer SCLC) without lymph node involvement. In this study, the results indicated that $\mathrm{PCl}$ does not reduce the risk of cerebral recurrence of resected $\mathrm{p}-\mathrm{T} 1-2 \mathrm{~N} 0 \mathrm{MO} \mathrm{SCLC}$. This is the largest sample size study focused on $\mathrm{PCl}$ in resected $\mathrm{p}-\mathrm{T} 1-\mathrm{NOMO}$ SCLC. Future revised versions of the guidelines should address this issue.

3 Paximadis $\mathrm{P}$, Beebe-

Comparing Treatment

2018 Sep;19(5):e559-e565. doi:

Dimmer JL, George J,

Schwartz AG, Wozniak

Strategies for Stage I Small-

cell lung Cancer. Clin Lung

Cancer. 10.1016/j.cllc.2018.03.017. Epub PMCID: PMC6152878. 2018 Mar 23. PMID: 29656869;

2678 In this hospital-based registry study, definitive surgical resection and use of chemotherapy resulted in improved survival for patients with early stage SCLC. For patients who are not candidates for surgery, SBRT may offer a survival benefit compared with standard EBRT.

4 Engelhardt KE, Coughlin Survival after adjuvant J J Thorac Cardiovasc Surg. 2019 JM, DeCamp MM, radiation therapy in localized Dec;158(6):1665-1677.e2. doi: Denlinger CE, Meyerson small cell lung cancer treated 10.1016/j.jtcvs.2019.08.031. Epub SL, Bharat A, Odell DD. with complete resection 2019 Sep 9. PMID: 31627955; PMCID: PMC7405041.

146 Although complete resection was accomplished in a minority of patients, for these patients survival was good. The addition of thoracic RT to complete resection does not appear to confer additional survival benefit.

5 Stinchcombe TE.

Current Treatments for Surgically Resectable, Limited-Stage, and Extensive-Stage Small Cell Lung Cancer

Oncologist. 2017 Dec;22(12):1510 - Review
1517. doi: 10.1634/ theoncologist.2017-0204. Epub 2017 Aug 4. PMID: 28778960; PMCID: PMC5728020.

6 Wei $\mathrm{S}$, Wei B, Tian J, Song X, Wu B, Hu P

Propensity Score Matching Analysis for the Role of Surgery in Small Cell Lung Oncol Res Treat. 2020;43(6):276288. doi: 10.1159/000506867. Epub 2020 May 11. PMID: 32392569. Cancer

7 Rucker AJ, Raman V, Jawitz OK, Voigt SL, Tong BC, D'Amico TA, Harpole DH.

Effect of Lymph Node

Ann Thorac Surg. 2020 Assessment on Outcomes in Surgery for Limited Stage Small Cell Lung Cancer

Dec;110(6):1854-1860. do

10.1016/j.athoracsur.2020.04.117.

Epub 2020 Jun 13. PMID: 32544452; PMCID: PMC7958968. This review will provide an update on the standard therapies for surgically resected, limited-stage small cell lung cancer and extensive-stage small cell lung cancer that have been investigated in recent clinical trials. surgery, including N1-2 disease. However, patients with a tumour size $>5.0 \mathrm{~cm}$ or advanced T stage may be unable to benefit from surgery.

,051 In this study, there was no clear difference in survival based on increasing the number of lymph nodes assessed during lobectomy for limited stage SCLC. However, the number of retrieved lymph nodes was associated with pathologic nodal upstaging. Therefore patients may benefit from retrieval of more than seven lymph nodes during lobectomy for SCLC.

8 Yao $Y$, Zhou Y, Yang Z Huang $\mathrm{H}$, Shen $\mathrm{H}$.

Adjuvant Chemotherapy

Oncol Res. 2019 Feb 5;27(2):203-

110 These findings suggest that the application of adjuvant Following Surgical Resection 210. doi: 10.3727/096504018X Improves Survival in Patients 15202953107093. Epub 2018 With Early Stage Small Cell Mar 9. PMID: 29523217; PMCID: Lung Cancer PMC7848360 chemotherapy following pulmonary lobectomy is associated with improvements of survival prognoses for patients with SCLC. The combination of surgical intervention with conventional therapy should be taken into consideration as a prospective multidisciplinary regimen for early stage SCLC.

9 Liu Y, Shan L, Shen J, Liu Choice of surgical

Thorac Cancer. 2019

$\mathrm{L}$, Wang J, He J, He Q, procedure - lobectomy,

Apr;10(4):593-600. doi:

548 Lobectomy correlated with superior survival. For patients Jiang $L$, Guo $M$, Chen $X$, segmentectomy, or wedge Zeng $\mathrm{H}$, Xia $\mathrm{X}$, Peng $\mathrm{G}$, resection - for patients with Liang $W$, He J. stage T1-2NOMO small cell lung cancer: A populationbased study

10 Wang $Y$, Pang Z, Chen X, Development and validation Yan T, Liu J, Du J. of a prognostic model of resectable small-cell lung cancer: a large populationbased cohort study and external validation

11 Zhao X, Kallakury B, Surgical Resection of SCLC: Chahine JJ, Hartmann D, Prognostic Factors and the Zhang Y, Chen Y, Zhang Tumor Microenvironment $\mathrm{H}$, Zhang B, Wang C, Giaccone G.

10.1111/1759-7714.12943. Epub 2019 Mar 10. PMID: 30854808; PMCID: PMC6449329.

J Transl Med. 2020 Jun 15;18(1):237. doi: 10.1186/s12967020-02412-x. PMID: 32539859; PMCID: PMC7296644.

Thorac Oncol. 2019 May;14(5):914-923. doi: 10.1016/j. jtho.2019.01.019. Epub 2019 Feb 5. PMID: 30735815; PMCID: PMC6510981. in which lobectomy is unsuitable, prognosis following segmentectomy appears to be better than after wedge resection.

1052 A novel nomogram and risk stratification system was built, integrating clinicopathological characteristics and surgical procedure for resectable SCLC. The mode showed superior prediction ability for resectable SCLC.

205 Resected stage II SCLC patients have similar survival as stage I, suggesting that surgery could be extended to patients with hilar lymph node involvement. Survival was better in tumours with a higher percentage of T cells and $B$ cells, whereas PD-L1 expression in tumour cells and TILs correlated with worse survival, which suggests a potential role of immunotherapy in resected SCLC. 


\begin{tabular}{|c|c|c|c|c|c|}
\hline No. & Authors & Title & Source & $\begin{array}{c}\text { No. of } \\
\text { patients }\end{array}$ & Conclusions \\
\hline 12 & $\begin{array}{l}\text { Guo Y, Yang L, Liu L, Wei } \\
\text { J, Teng F, Zhang J, Zhu } \\
\text { Y, Xing P, Li J. }\end{array}$ & $\begin{array}{l}\text { Comparative study of } \\
\text { clinicopathological } \\
\text { characteristics and prognosis } \\
\text { between combined and pure } \\
\text { small cell lung cancer (SCLC) } \\
\text { after surgical resection }\end{array}$ & $\begin{array}{l}\text { Thorac Cancer. } 2020 \\
\text { Oct;11(10):2782-2792. doi: } \\
\text { 10.1111/1759-7714.13591. Epub } \\
2020 \text { Aug 11. PMID: } 32779385 ; \\
\text { PMCID: PMC7529571. }\end{array}$ & 297 & $\begin{array}{l}\text { This study demonstrated the prognosis of C-SCLCs did } \\
\text { not significantly differ from that of P-SCLCS, but was } \\
\text { more susceptible to the extent of resection. Patients } \\
\text { with C-SCLC who underwent limited resection had a } \\
\text { significantly increased risk of shorter OS. The study } \\
\text { highlighted the importance of performing lobectomy for } \\
\text { resectable C-SCLC patients. It also proved the benefit of } \\
\text { PCI in improving the OS rate for both P-SCLC and C-SCLC } \\
\text { patients. }\end{array}$ \\
\hline 13 & $\begin{array}{l}\text { Pan Y, Kong FW, Wang } \\
\mathrm{H} \text {, Wang X, Zhang H, Wu } \\
\text { WB, Zhang M. }\end{array}$ & $\begin{array}{l}\text { A recurrence-free survivor } \\
\text { with chemotherapy- } \\
\text { refractory small cell } \\
\text { lung cancer after } \\
\text { pneumonectomy: A case } \\
\text { report and review of the } \\
\text { literature }\end{array}$ & $\begin{array}{l}\text { Medicine (Baltimore). } 2017 \\
\text { Nov;96(47):e8922. doi: 10.1097/ } \\
\text { MD.0000000000008922. PMID: } \\
\text { 29382030; PMCID: PMC5709029. }\end{array}$ & $\begin{array}{l}\text { Case } \\
\text { report } \\
\text { and } \\
\text { review }\end{array}$ & $\begin{array}{l}\text { For patients with chemotherapy-resistant but resectable } \\
\text { SCLC, a timely resection combined with postoperative } \\
\text { radiotherapy and apatinib might be effective. }\end{array}$ \\
\hline 14 & $\begin{array}{l}\text { Zeng Q, Li J, Tan F, Sun } \\
\text { N, Mao Y, Gao Y, Xue Q, } \\
\text { Gao S, Zhao J, He J. }\end{array}$ & $\begin{array}{l}\text { Development and Validation } \\
\text { of a Nomogram Prognostic } \\
\text { Model for Resected Limited- } \\
\text { Stage Small Cell Lung Cancer } \\
\text { Patients }\end{array}$ & $\begin{array}{l}\text { Ann Surg Oncol. } 2021 \\
\text { Sep;28(9):4893-4904. doi: 10.1245/ } \\
\text { s10434-020-09552-w. Epub } 2021 \\
\text { Mar 2. PMID: 33655361; PMCID: } \\
\text { PMC8349336. }\end{array}$ & 1006 & $\begin{array}{l}\text { The authors developed and validated novel nomograms } \\
\text { for individual prediction of survival for resected limited- } \\
\text { stage SCLC patients. These models performed better } \\
\text { than the previously widely-used staging system, and may } \\
\text { offer clinicians instructions for strategy making and the } \\
\text { design of clinical trials. }\end{array}$ \\
\hline
\end{tabular}

\section{DESCRIPTION OF THE STATE OF KNOWLEDGE}

The role of pulmonary resection in early SCLC has been controversial for many decades [6]. Undoubtedly, it constitutes a valuable component of a combined modality treatment, especially in the situation when a small peripheral lesion detected at low-dose computed tomography (LDCT) is re-sected, and after the resection the diagnosis of SCLC is established $[9,10]$. However, many lung physicians do not refer patients with small peripheral pulmonary lesions for thoracic surgical resection when SCLC is suspected, but prefer observation. Additionally, SCLC is often diagnosed at a late stage of development when chances of a cure are critically low.

In the $21^{\text {st }}$ century, the capabilities of contemporary medicine regarding early diagnosis of pulmonary lesions improved significantly. Development of new diagnostic endoscopic techniques, e.g. endobronchial ultrasound (EBUS), or ithe ntroduction of low-dose computed tomography (LDCT) screening programmes, allowed the detection of pulmonary malignancies, including SCLC, at very early stages [22]. In classic chemo-radiotherapy regimens applied for SCLC, the local failure rate can be up to $50 \%$, and still remains a major problem in the management of locally advanced cases $[3,4]$. To-date, the role of surgery in SCLC has been barely defined so far, and historically, surgery alone has been reported to be ineffective $[5,6]$. However, as in the case of other solid tumourrs, including non-small cell lung cancer (NSCLC), surgical resection of the primary tumour supported by chemo- and radiotherapy is considered to offer certain benefits in locally advanced cases of SCLC, especially in terms of local control and long-term survival.

Zhong et al. in their report on the prognosis of limitedstage small cell lung cancer with comprehensive treatment, including radical resection, concluded that for limited-stage SCLC patients the comprehensive treatment including radical surgery may be superior to concurrent chemoradiotherapy [8]. Also, Stinchcombe et al. in a study on current treatments for surgically resectable, limited-stage, and extensive-stage SCLC, provided an update on the standard therapies for surgically resected limited-stage small cell lung cancer, emphesiszing that surgical resection has became nowadays a mainstem of effective therapy in such cases [12].

Prophylactic cranial irradiation (PCI) remains controversial for resected small-cell lung cancer SCLC) without lymph node involvement. Lou $\mathrm{Y}$ et al. indicated that PCI does not reduce the risk of cerebral recurrence of resected $\mathrm{p}-\mathrm{T} 1-$ 2N0M0 SCLC. The presented report is the largest sample size study focused on PCI in resected p-T1-N0M0 SCLC. The authors emphasize that future revised versions of the guidelines should address this issue [9].

Paximadis et al. in a large cohort hospital-based registry study showed that definitive surgical resection and use of chemotherapy resulted in improved survival for patients with early stage SCLC. Radiotherapy may offer a considerable option only for patients who are not candidates for surgery [10]. Similar results were attained by Engelhardt et al. in their study on survival after adjuvant radiation therapy in localized small cell lung cancer treated with complete resection [11]. The authors showed that although complete resection was accomplished in a minority of patients, for these patients survival was good. The addition of thoracic radiotherapy to complete resection does not appear to confer additional survival benefit.

Even patients with mediastinal lymph nodes involvement, including N1-2 disease, can benefit from surgery. However, patients with tumour size $>5.0 \mathrm{~cm}$ or advanced $\mathrm{T}$ stage may be unable to benefit from surgery [13]. This issue was also analyzed by Rucker et al. in a study on the effect of lymph node assessment on outcomes in surgery for limited stage small cell lung cancer. The authors described no clear difference in survival based on increasing the number of lymph nodes assessed during lobectomy for limited stage SCLC, but showed that in patients with SCLC, even larger anatomical resections can be safely performed [14].

Yao et al. presented findings suggesting that the application of adjuvant chemotherapy following pulmonary lobectomy is associated with improvements of survival prognoses for patients with SCLC. They concluded that the combination of surgical intervention with conventional therapy should be taken into consideration as a prospective multidisciplinary regimen for early stage SCLC [15]. Similar conclusions were 
reported by Liu et al., who found that in patients with SCLC, lobectomy correlated with superior survival. Furthermore, for patients in whom lobectomy was unsuitable, prognosis following segmentectomy appeared to be better than after wedge resection [16].

Wang et al. built a novel nomogram and risk stratification system which integrated clinicopathological characteristics and surgical procedure for resectable SCLC. The model showed superior prediction ability for resectable SCLC [17].

As proved by Zhao et al., resected stage II SCLC patients have similar survival as stage I, suggesting that surgery could be extended to patients with hilar lymph node involvement. Survival was better in tumours with a higher percentage of T cells and B cells, whereas PD-L1 expression in tumour cells and TILs correlated with worse survival, which suggests a potential role of immunotherapy in resected SCLC [18]. It is worth noting that according to a report by Guo et al. the prognosis of combined SCLCs (C-SLCS) did not significantly differ from that of pure SCLCs (P-SCLC), but was more susceptible to the extent of resection [19]. Patients with C-SCLC who underwent limited resection had a significantly increased risk of shorter overall survival. This study highlighted the importance of performing lobectomy for resectable C-SCLC patients. Pan et al. and Zeng et al. also confirmed that surgical removal of the primary lesion in patients with SCLC is safe and effective, even when a larger extent of resection is necessary [20,21].

Considering, that both patients with SCLC and non-small cell lung cancer (NSCLC), benefit from surgical removal of the primary lesion, it becomes clear that histologically indeterminate pulmonary lesions suspected of malignancy (Fig. 1) should be obligatorily consulted by thoracic surgeons. Whenever clinically possible, the lesion should be re-sected, preferably with an intra-operative frozen section [25]. If

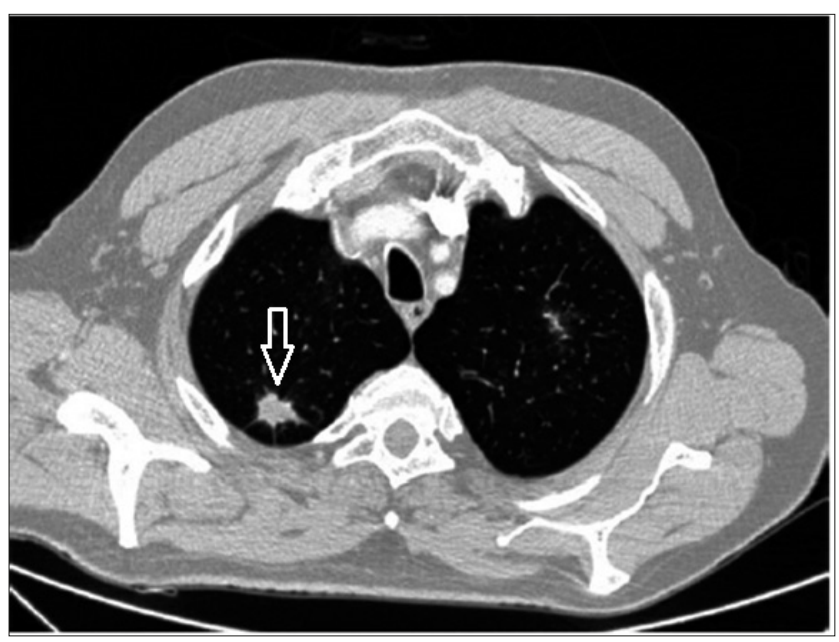

Figure 1. Computed tomography scan showing a pulmonary lesion in the right lung (The lesion is indicated with a white arrow). The lesion was resected, and diagnosed as SCLC by intraoperative frozen section

histologic diagnosis reveals SCLC, postoperatively the patient should be assessed by an oncologist and considered a candidate for adjuvant chemotherapy or chemo-radiotherapy. This regimen is widely accepted in most of the recommendations $[3,4,7,23]$.

To provide high precision of assessment, SCLC is nowadays preferably staged using the $8^{\text {th }}$ edition of the TNM lung cancer staging system. TNM staging is a tumour classification system which, in principle, reflects the anatomic extent of the tumour based on the extent of the primary tumour $(\mathrm{T})$, the nodal spread $(\mathrm{N})$, and the distant metastases $(\mathrm{M})$. A recent revision to the 8 th edition has been made to achieve refined prognostic capabilities and to help clinicians stratify tumors based on expected prognosis. It is widely applied in many recent publications, because appropriate staging is crucial for clinical evaluation of lung cancer patients and for the selection of optimal management strategy [24].

Surgical pulmonary resection offers patients with SCLC considerable therapeutic benefits. Clinical reports showed that local relapse rate in patients after surgical resection was significantly lower than in the non-surgical group (18\% vs. $46 \%$, respectively) [22]; however, the distant metastases rate was slightly higher. Authors of reports on surgical resection of SCLC emphasize the importance of complete resection (R0) for preventing local relapse $[24,16]$. In Eberhardt's series, patients with completely re-sected lesion (R0) experienced no local relapse, but in $52 \%$ of these patients distant metastases were detected in the follow-up [22]. Other authors reported similarly beneficial observations in patients undergoing pulmonary resections for early stage SCLC $[3,6,26,27]$.

Furthermore, many authors report median survival and 5 -year survival rate in patients after complete resection to be better than in non-surgical groups $[25,26]$. For patients with stage I SCLC, the five-year survival rate attained 64\% in selected series [26]. For stage II patients, the survival rate drops to $45 \%$, which is probably due to a high percentage of N2 cases, which have a strong negative impact on survival [28]. Analysis of published reports reveals that favourably high survival rates were limited to precisely selected stage I and stage II patients, which should be advised when qualifying patients with SCLC for surgical pulmonary resection.

\section{SUMMARY}

Current scientific and clinical data reveal that pulmonary resection of an early stage SCLC as a component of combined treatment, providing completeness of the resection (R0), offers considerable therapeutic benefits, among them almost $100 \%$ local control which is of the greatest importance. The major aim of adjuvant systemic modalities, including chemotherapy and radiotherapy, is to eradicate clinically undetected micrometastases. This is due to the fact that at the time of diagnosis SCLC is often a subclinically disseminated disease. Up-to-date clinical strategies strongly support the recommendation that peripheral pulmonary lesions suspected to be malignant, should be re-sected, unless serious contraindications exist.

\section{REFERENCES}

1. Barnes H, See K, Barnett S, Manser R. Surgery for limited-stage small-cell lung cancer. Cochrane Database Syst Rev. 2017 Apr 21;4(4):CD011917. doi: 10.1002/14651858.CD011917.pub2.

2. Wang Y, Zou S, Zhao Z, Liu P, Ke C, Xu S. New insights into smallcell lung cancer development and therapy. Cell Biol Int. 2020 Aug;44(8):1564-1576. doi: 10.1002/cbin.11359. Epub 2020 Apr 18.

3. Xu L, Zhang G, Song S, Zheng Z. Surgery for small cell lung cancer: A Surveillance, Epidemiology, and End Results (SEER) Survey from 2010 
to 2015. Medicine (Baltimore). 2019 Oct;98(40):e17214. doi: 10.1097/ MD.0000000000017214.

4.Zhao H, Ren D, Liu H, Chen J. Comparison and discussion of the treatment guidelines for small cell lung cancer. Thorac Cancer. 2018 Jul;9(7):769-774. doi: 10.1111/1759-7714.12765. Epub 2018 May 16.

5. Low M, Ben-Or S. Thoracic Surgery in Early-Stage Small Cell Lung Cancer. Thorac Surg Clin. 2018 Feb;28(1):9-14. doi: 10.1016/j. thorsurg.2017.08.003. Epub 2017 Oct 18.

6.van Meerbeeck JP, Fennell DA, De Ruysscher DK. Small-cell lung cancer. Lancet. 2011 Nov 12;378(9804):1741-55. doi: 10.1016/S01406736(11)60165-7. Epub 2011 May 10.

7. Veronesi G, Bottoni E, Finocchiaro G, Alloisio M. When is surgery indicated for small-cell lung cancer? Lung Cancer. 2015 Dec;90(3):582-9. doi: 10.1016/j.lungcan.2015.10.019. Epub 2015 Oct 17.

8.Zhong L, Suo J, Wang Y, Han J, Zhou H, Wei H, Zhu J. Prognosis of limited-stage small cell lung cancer with comprehensive treatment including radical resection. World J Surg Oncol. 2020 Feb 3;18(1):27. doi: 10.1186/s12957-020-1807-1. PMID: 32013993; PMCID: PMC6998207.

9. Lou Y, Zhong R, Xu J, Qiao R, Teng J, Zhang Y, Zhang X, Chu T, Zhong $\mathrm{H}$, Han B. Does surgically resected small-cell lung cancer without lymph node involvement benefit from prophylactic cranial irradiation? Thorac Cancer. 2020 May;11(5):1239-1244. doi: 10.1111/1759-7714.13381. Epub 2020 Mar 6. PMID: 32142599; PMCID: PMC7180625.

10. Paximadis P, Beebe-Dimmer JL, George J, Schwartz AG, Wozniak A, Gadgeel S. Comparing Treatment Strategies for Stage I Smallcell lung Cancer. Clin Lung Cancer. 2018 Sep;19(5):e559-e565. doi: 10.1016/j.cllc.2018.03.017. Epub 2018 Mar 23. PMID: 29656869; PMCID: PMC6152878.

11. Engelhardt KE, Coughlin JM, DeCamp MM, Denlinger CE, Meyerson SL, Bharat A, Odell DD. Survival after adjuvant radiation therapy in localized small cell lung cancer treated with complete resection. J Thorac Cardiovasc Surg. 2019 Dec;158(6):1665-1677.e2. doi: 10.1016/j. jtcvs.2019.08.031. Epub 2019 Sep 9. PMID: 31627955; PMCID: PMC7405041.

12. Stinchcombe TE. Current Treatments for Surgically Resectable, LimitedStage, and Extensive-Stage Small Cell Lung Cancer. Oncologist. 2017 Dec;22(12):1510-1517. doi: 10.1634/theoncologist.2017-0204. Epub 2017 Aug 4. PMID: 28778960; PMCID: PMC5728020.

13. Wei S, Wei B, Tian J, Song X, Wu B, Hu P. Propensity Score Matching Analysis for the Role of Surgery in Small Cell Lung Cancer. Oncol Res Treat. 2020;43(6):276-288. doi: 10.1159/000506867. Epub 2020 May 11. PMID: 32392569.

14. Rucker AJ, Raman V, Jawitz OK, Voigt SL, Tong BC, D’Amico TA, Harpole DH. Effect of Lymph Node Assessment on Outcomes in Surgery for Limited Stage Small Cell Lung Cancer. Ann Thorac Surg. 2020 Dec;110(6):1854-1860. doi: 10.1016/j.athoracsur.2020.04.117. Epub 2020 Jun 13. PMID: 32544452; PMCID: PMC7958968.

15. Yao Y, Zhou Y, Yang Z, Huang H, Shen H. Adjuvant Chemotherapy Following Surgical Resection Improves Survival in Patients With Early Stage Small Cell Lung Cancer. Oncol Res. 2019 Feb 5;27(2):203-210. doi: 10.3727/096504018X15202953107093. Epub 2018 Mar 9. PMID: 29523217 ; PMCID: PMC7848360.

16. Liu Y, Shan L, Shen J, Liu L, Wang J, He J, He Q, Jiang L, Guo M, Chen X, Zeng H, Xia X, Peng G, Liang W, He J. Choice of surgical procedure lobectomy, segmentectomy, or wedge resection - for patients with stage T1-2N0M0 small cell lung cancer: A population-based study. Thorac
Cancer. 2019 Apr;10(4):593-600. doi: 10.1111/1759-7714.12943. Epub 2019 Mar 10. PMID: 30854808; PMCID: PMC6449329.

17. Wang Y, Pang Z, Chen X, Yan T, Liu J, Du J. Development and validation of a prognostic model of resectable small-cell lung cancer: a large population-based cohort study and external validation. J Transl Med. 2020 Jun 15;18(1):237. doi: 10.1186/s12967-020-02412-x. PMID: 32539859; PMCID: PMC7296644.

18. Zhao X, Kallakury B, Chahine JJ, Hartmann D, Zhang Y, Chen Y, Zhang H, Zhang B, Wang C, Giaccone G. Surgical Resection of SCLC: Prognostic Factors and the Tumor Microenvironment. J Thorac Oncol. 2019 May;14(5):914-923. doi: 10.1016/j.jtho.2019.01.019. Epub 2019 Feb 5. PMID: 30735815; PMCID: PMC6510981.

19. Guo Y, Yang L, Liu L, Wei J, Teng F, Zhang J, Zhu Y, Xing P, Li J. Comparative study of clinicopathological characteristics and prognosis between combined and pure small cell lung cancer (SCLC) after surgical resection. Thorac Cancer. 2020 Oct;11(10):2782-2792. doi: 10.1111/17597714.13591. Epub 2020 Aug 11. PMID: 32779385; PMCID: PMC7529571.

20. Pan Y, Kong FW, Wang H, Wang X, Zhang H, Wu WB, Zhang M. A recurrence-free survivor with chemotherapy-refractory small cell lung cancer after pneumonectomy: A case report and review of the literature. Medicine (Baltimore). 2017 Nov;96(47):e8922. doi: 10.1097/ MD.0000000000008922. PMID: 29382030; PMCID: PMC5709029.

21.Zeng Q, Li J, Tan F, Sun N, Mao Y, Gao Y, Xue Q, Gao S, Zhao J, He J. Development and Validation of a Nomogram Prognostic Model for Resected Limited-Stage Small Cell Lung Cancer Patients. Ann Surg Oncol. 2021 Sep;28(9):4893-4904. doi: 10.1245/s10434-020-09552-w. Epub 2021 Mar 2. PMID: 33655361; PMCID: PMC8349336.

22. Eberhardt W, Stamatis G, Stuschke M et al. Prognostically oriented multimodality treatment including surgery for selected patients of small-cell lung cancer patients stages IB to IIIB: long term results of a phaseII trial. Brit J Cancer 1999;81(7):1206-12.

23. National Lung Screening Trial Research Team. Lung Cancer Incidence and Mortality with Extended Follow-up in the National Lung Screening Trial. J Thorac Oncol. 2019 Oct;14(10):1732-1742. doi: 10.1016/j. jtho.2019.05.044. Epub 2019 Jun 28.

24. Li J, Zhao Y, Li C, Zhu L, Liu C, Liu L. The revision of 8th edition TNM stage criteria is more accurate in prediction postoperative survival for SCLC patients. Int J Surg. 2017 Dec;48:83-85. doi: 10.1016/j. ijsu.2017.09.072. Epub 2017 Oct 5.

25. Casiraghi M, Sedda G, Del Signore E, Piperno G, Maisonneuve P, Petrella F, de Marinis F, Spaggiari L. Surgery for small cell lung cancer: When and how. Lung Cancer. 2021 Feb;152:71-77. doi: 10.1016/j. lungcan.2020.12.006. Epub 2020 Dec 22.

26. D'Amico TA. Commentary: Surgery for small cell lung cancer: This is the way. J Thorac Cardiovasc Surg. 2021 Mar;161(3):772-773. doi:10.1016/j. jtcvs.2020.11.090. Epub 2020 Nov

27. de Hoyos A, DeCamp MM. Surgery for small cell lung cancer. Thorac Surg Clin. 2014 Nov;24(4):399-409. doi: 10.1016/j.thorsurg.2014.07.005. Epub 2014 Sep 6.

28. Chenesseau J, Bourlard D, Cluzel A, Trousse D, D'Journo XB, Thomas $\mathrm{PA}$. Intent-to-cure surgery for small-cell lung cancer in the era of contemporary screening and staging methods. Interact Cardiovasc Thorac Surg. 2020 Apr 1;30(4):541-545. doi: 10.1093/icvts/ivz299

29. Schneider BJ, Saxena A, Downey RJ. Surgery for early-stage small cell lung cancer. J Natl Compr Canc Netw. 2011 Oct;9(10):1132-9. doi: 10.6004/jnccn.2011.0094. 